\title{
Forearm bone mineral density in postmenopausal Indian women: correlation with calcium nutrition
}

\author{
Swati Sharma ${ }^{1 *}$, Bhavna Agarwal' ${ }^{2}$, Rohit Sharma ${ }^{3}$, Simarpreet Singh $^{3}$
}

\author{
${ }^{1}$ Department of Obstetrics and Gynecology, Sri Guru Ram Dass Institute of Medical Science and Research, Amritsar, \\ Punjab, India \\ ${ }^{2}$ Consultant Obstetrics and Gynecology, Balaji Medicentre, Panchkula, Haryana, India \\ ${ }^{3}$ Department of Orthopaedics, Sri Guru Ram Dass Institute of Medical Science and Research, Amritsar, Punjab, India
}

Received: 06 September 2017

Accepted: 12 September 2017

\section{*Correspondence:}

Dr. Swati Sharma,

E-mail: suriswati26@gmail.com

Copyright: ( ) the author(s), publisher and licensee Medip Academy. This is an open-access article distributed under the terms of the Creative Commons Attribution Non-Commercial License, which permits unrestricted non-commercial use, distribution, and reproduction in any medium, provided the original work is properly cited.

\begin{abstract}
Background: Osteoporosis is characterized by low bone mass with micro architectural deterioration of bone tissue leading to enhanced bone fragility, thus increasing the susceptibility to fracture. This study was conducted with the objective of measuring forearm bone mineral density in postmenopausal Indian women and to establish a correlation with indices of calcium nutrition i.e. dietary calcium intake, calcium supplements, serum calcium, serum phosphorus, serum alkaline phosphatase and serum intact parathyroid hormone.

Methods: Fifty healthy, ambulatory postmenopausal women were selected and a prospective observational study was conducted to correlate the BMD with indices of calcium nutrition. Patient's laboratory investigations (serum calcium, serum phosphorous, serum alkaline phosphatase and serum intact parathyroid hormone were done and BMD was assessed with dual-energy X-ray absorptiometry at non-dominant forearm; T-scores and Z-score were derived. Correlation analysis was done to investigate the relationship between indices of calcium nutrition and BMD.

Results: The proportion of osteoporosis in forearm was $22 \%$ in the deficient group, $60 \%$ in the insufficient group and $18 \%$ in the sufficient group. Among the study group 15 subjects were osteoporotic by T score mid forearm where as 7 were osteoporotic with $\mathrm{T}$ score ultra distal forearm and 11 subjects had osteoporosis with $\mathrm{T}$ score total forearm.

Conclusions: Out of all the indices of calcium nutrition, the correlation between the serum alkaline phosphatase and $\mathrm{T}$ score forearm was statistically significant.
\end{abstract}

Keywords: Bone mineral density, Osteoporosis, Postmenopausal women, Serum calcium, Serum phosphorous, Serum alkaline phosphatase, Serum intact parathyroid hormone

\section{INTRODUCTION}

Osteoporosis is characterized by low bone mass with micro architectural deterioration of bone tissue leading to enhance bone fragility, thus increasing the susceptibility to fractue. ${ }^{1}$ With the increase in life expectancy, osteoporosis has become a formidable public health problem in India. While data on prevalence of osteoporosis among women in India come from studies conducted in small groups spread across the country, estimates suggest that of the 230 million Indians expected to be over the age of 50 years in $2015,20 \%$, i.e., about 46 million, are women with osteoporosis. ${ }^{2}$

Osteoporosis may be primary or secondary to a clearly identifiable etiological mechanism. Primary osteoporosis can be classified in to postmenopausal and senile. Postmenopausal osteoporosis relates to bone loss due to 
loss of estrogen and results in excess loss of cancellous bone. In senile osteoporosis there is concordant loss of cortical and cancellous bone. This presumably is a result of age related calcium malabsorption due to a decline in renal production of 1,25 dihydroxy vitamin D $[1,25(\mathrm{OH}) \mathrm{D}]$ and decreased response of the intestine to it. ${ }^{3}$

The mean calcium intake was estimated to be $323 \mathrm{mg}$ per day in south Indian women according to Harinarayan ${ }^{4}$ whereas Arya et al reported daily dietary calcium intake in north Indian women to be $438.6 \mathrm{mg} .^{5}$

Dairy produce is the major source of calcium however in India dairy products are expensive and often in scarce supply. Caffeine intake increases urinary and intestinal calcium secretion and excessive consumption of caffeine containing drinks like coffee, tea may predispose to osteoporosis. ${ }^{6}$ Physiologically a decrease in calcium intake and/or absorption lowers the serum level of ionized calcium. This stimulates parathyroid hormone (PTH) secretion to mobilize calcium from bone by direct stimulation of osteoclastic activity. Increased PTH also stimulates the production of Vitamin D to increase intestinal calcium absorption. Serum calcium level increases and PTH level returns to normal. Chronic calcium and/ or vitamin D deficiency subsequently results in secondary hyperparathyroidism.

A deficiency in estrogen is associated with a greater responsiveness of bone to PTH. Thus for any given level of serum PTH in menopausal women there is more calcium removed from bone, raising serum calcium, which, in turn, lowers PTH and decreases vitamin D and intestinal absorption of calcium. ${ }^{7}$ The various diagnostic modalities for measurement of bone mineral density are dual energy X-ray absorptiometry (DEXA), quantitative ultrasonography (QUS), quantitative computerized tomography (QCT), single photon absorptiometry (SPA) and single energy X-ray absorptiometry (SXA), of which DEXA is the gold standard. X-ray can diagnose osteoporosis only after the bone mineral density (BMD) is lost by $20-30 \%$. DEXA offers the advantage of higher precision, minimal ionizing radiation, rapid screening time and ability to assess the cortical and trabecular bone mass of the appendicular and axial sites. ${ }^{8}$

Tools like DEXA for estimating BMD are not yet easily available in India. Very few centers are equipped with these facilities. Besides the level of awareness in general population regarding this sophisticated but important investigation is very low. Thus, not much data pertaining to Indian population with reference to BMD is available at present.

This current study is designed with an aim to assess the forearm bone mineral density in postmenopausal Indian women and its correlation with indices of calcium nutrition.

\section{METHODS}

This is a prospective and observational study conducted at Department of Obstetrics and Gynecology in collaboration with Department of Orthopedics, Sri Guru Ram Das Institute of Medical Science and Research, Amritsar, Punjab from May 2016 to December 2016. 50 healthy, ambulatory postmenopausal women were enrolled after they were informed about the purpose of the study. The exclusion criteria were presence of any endocrinal, renal, active liver disease, pulmonary or cardiac disease, major rheumatoid disease, malignancies, immobilization, and long-term treatment with cortisone, anabolic steroids, anticonvulsants and heparin.

Selected patients underwent detailed history and examination. A questionnaire seeking information on menopausal status, family history of osteoporosis, gynaecological history, number of pregnancies, whether currently taking calcium supplements or hormone replacement therapy in the past, sustained any fragility fracture in the past and life style factors such as alcohol intake, smoking status, type of diet, daily consumption of dairy products, exposure to sunlight and exercise. A positive family history was recorded when the women had a first degree women relative who had sustained a fragility fracture of the hip or wrist or developed a curvature of the spine as a result of osteoporosis. A fragility fracture has been defined by the World Health Organization as 'a fracture caused by injury that would be insufficient to fracture normal bone: the result of reduced compressive and/ or torsional strength of bone'. A diet of dairy products (milk, curd and paneer) was recorded to calculate the daily calcium intake.

\section{Biochemical measurements}

Fasting venous samples were drawn to estimate serum calcium (ref.range 8.4-10.2 mg/dl), serum phosphorous (ref.value $2.7-4.5 \mathrm{mg} / \mathrm{dl}$ ), serum alkaline phosphatase (ref.range 39-117IU/dl) and serum intact parathyroid hormone (ref.value. 9-55pg/ml). The serum intact parathyroid hormone was measured using two site immuno-radiometric assay.

\section{Bone mineral density}

DEXA scan was performed on the same day to determine bone mineral density at the non-dominant forearm. The forearm measurement was obtained with the patient seated, the arm resting on the table and straight in relation to the table's long axis. BMD was estimated by Hologic QDR 4500 which is a multiple detector, fan beam, dual energy X-ray densitometer. BMD, T-score and Z-score at the forearm was measured.

$\mathrm{T}$ score is the Standard deviations between patient and average peak young adult bone mass. The more negative values of $\mathrm{T}$ score, the greater the risk of fracture. $\mathrm{Z}$ score is the Standard deviation between patient and average 
bone mass for some age and weight. A Z score, lower than -2.0 , requires diagnostic evaluation for causes other than postmenopausal bone loss.

\section{According to WHO criteria}

- Normal: BMD within 1 S.D. of young adult reference range.

- Osteopenia: BMD more than 1 S.D. below the young adult mean but less than 2.5 S.D. below this value.

- Osteoporosis: A value of BMD 2.5 S.D. or more below young adult mean.

\section{Statistical analysis}

The statistical analysis of the data was done using SPSS package. One way ANNOVA and Pearson's correlation test were applied to the data in order to find the association of various variables as age, duration of menopause, weight, BMI, dietary habits with bone mineral density and $\mathrm{T}$ score of nondominant forearm.

\section{RESULTS}

During the six month study period, fifty healthy postmenopausal Indian women were enrolled and subjected to DEXA scan of non dominant forearm and blood investigations.

Table 1: The age of subjects enrolled in the present study.

\begin{tabular}{|l|l|}
\hline Age group & No. of cases \\
\hline $46-50$ years & 12 \\
\hline $51-55$ years & 13 \\
\hline $56-60$ years & 14 \\
\hline $61-65$ years & 7 \\
\hline $66-70$ years & 4 \\
\hline
\end{tabular}

The age of subjects enrolled in the present study ranged from 46 to 70 years. The mean (+SD) age of the study subjects was $55.78(+6.28)$ years. Maximum number of patients was in the 56-60 year age group (Table1).

Parity of the study subjects ranged from zero to six. The mean parity of the subjects was 2.8 .

Table 2: The duration of menopause for study subjects.

\begin{tabular}{|l|l|}
\hline Duration of menopause & Number of cases \\
\hline $1-5$ years & 20 \\
\hline $5-10$ years & 13 \\
\hline $11-15$ years & 17 \\
\hline
\end{tabular}

The duration of menopause for study subjects ranged from one to 15 years. The mean duration of menopause was 7.54 years (Table 2). Thirty four study subjects had no family history of osteoporosis where as other 16 of them had history of osteoporosis in family There was no association between $\mathrm{T}$ score forearm and family history of osteoporosis.

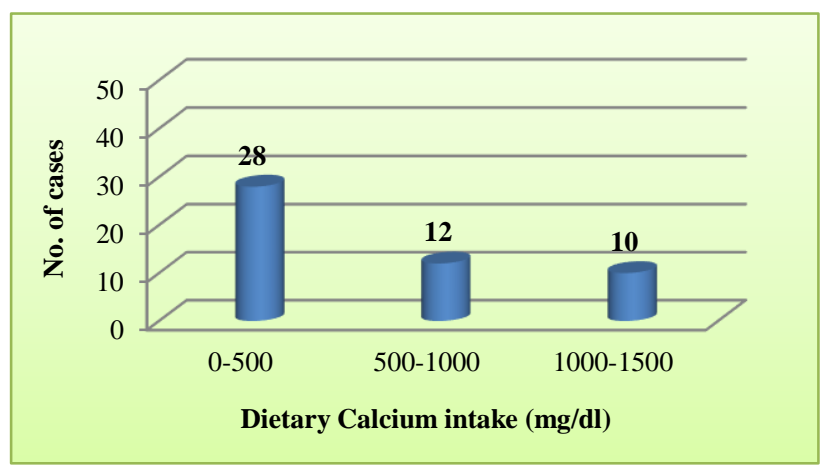

Figure 1: Dietary calcium intake.

On basis of recall of dietary history by the subjects, average calcium intake per day from dairy products was calculated. One glass of milk equals to $300 \mathrm{mg}$ calcium, one cup of curd has $415 \mathrm{mg}$ calcium and each serving of paneer (200 gm) has $415 \mathrm{mg}$ of calcium. The mean (+SD) daily dietary calcium intake was $539.3 \mathrm{gm}$ (+420.8 gm). 28 subjects had daily intake of dairy calcium less than $500 \mathrm{mg}, 12$ subjects had dairy calcium of 500-1000 mg and 10 subjects consumed 1000-1500 mg of dairy calcium each day.

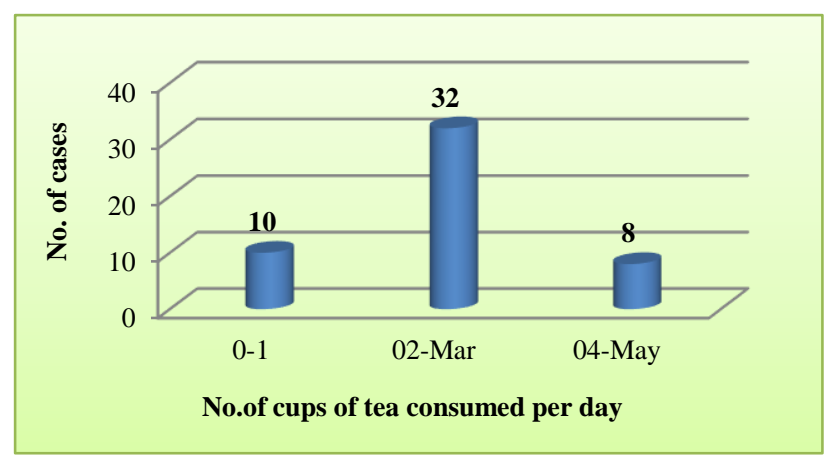

Figure 2: Frequency of tea consumption.

10 subjects consumed nil to one cup of tea per day, 32 subjects took 2-3 cups of tea per day and 8 subjects used to take 4-5 cups of tea per day. None of the subjects consumed coffee.

23 subjects had sedentary life style, 27did some form of physical activity mainly brisk walking. Hence we divided subjects in three groups: sedentary, brisk walking for less then $30 \mathrm{~min} /$ day and more then $30 \mathrm{~min} /$ day. Nineteen subjects had activity less than $30 \mathrm{~min} /$ day and 8 subjects had activity per day for more than 30 minutes.

Body mass index (BMI) of the study subjects ranged from 17.31-39.48 $\mathrm{kg} / \mathrm{m}^{2}$. Average BMI of the subjects was $28.17 \mathrm{~kg} / \mathrm{m}^{2}$ (Table 3). 


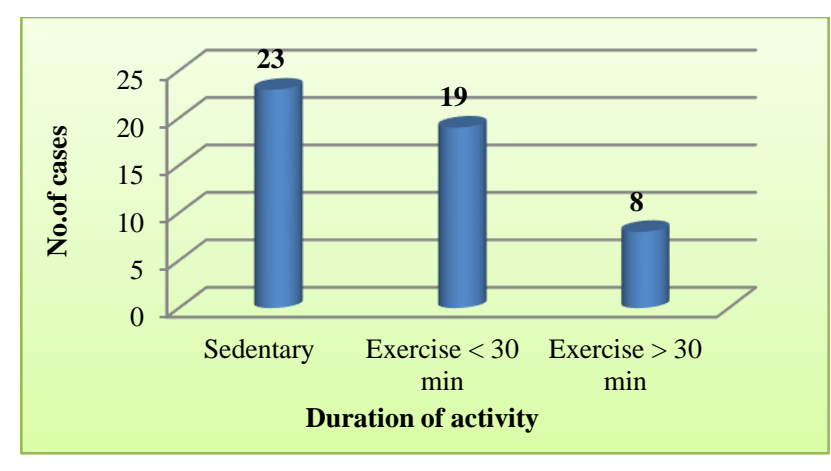

Figure 3: Physical activity.

Twelve subjects had BMI less than 25 where as 22 subjects had BMI 25-30 and 16 subjects had BMI more than $30 \mathrm{~kg} / \mathrm{m}^{2}$.

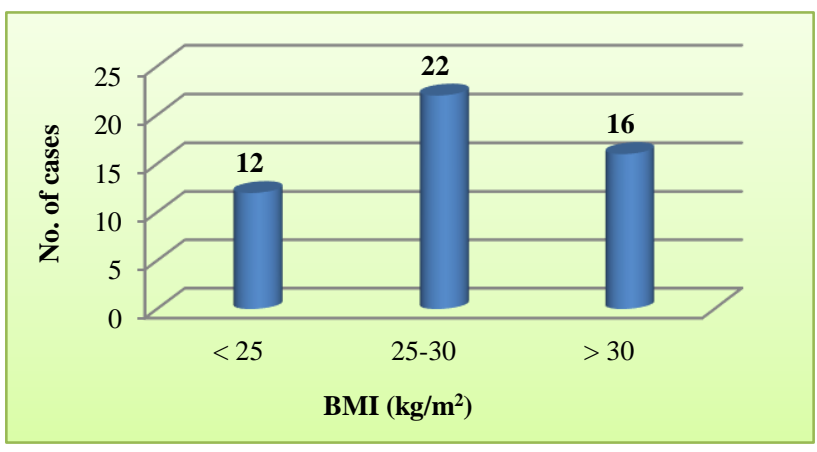

Figure 4: Distribution of body mass index.

Correlation with $\mathrm{T}$ score Forearm

The highest proportion of normal subjects was in the 4650 years group, whereas highest proportion of osteopenic was in 51-55 year age group and osteoporotic subjects in 56-60 year group. There was negative correlation between age and $\mathrm{T}$ score forearm which was statistically significant $(\mathrm{p}<0.05)$.

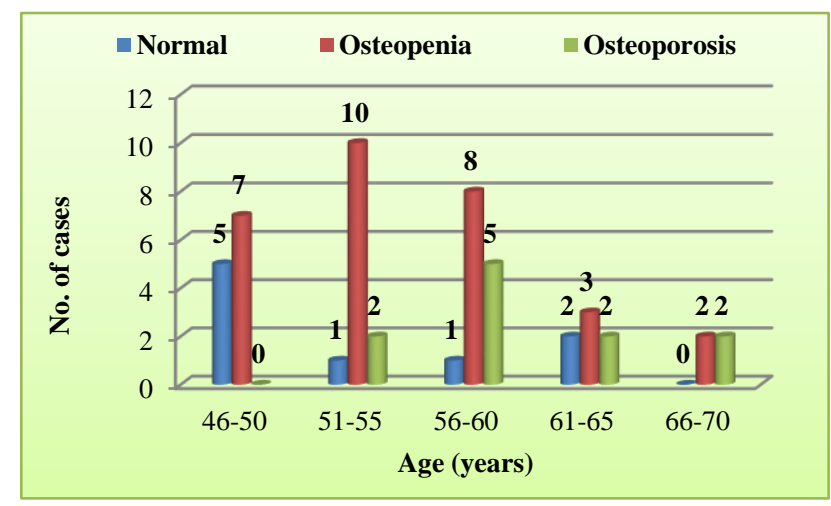

Figure 5: Correlation of age with $\mathbf{T}$ score forearm.

On comparing the duration of menopause with $\mathrm{T}$ score of forearm it was observed that maximum number of subjects developed osteopenia within 5 years of menopause whereas maximum number of subjects were osteoporotic between 6-10 years of menopause. There was negative correlation between forearm BMD and duration of menopause which is statistically significant $(p<0.05)$. This suggests that as the duration of menopause increases the forearm BMD decreases.

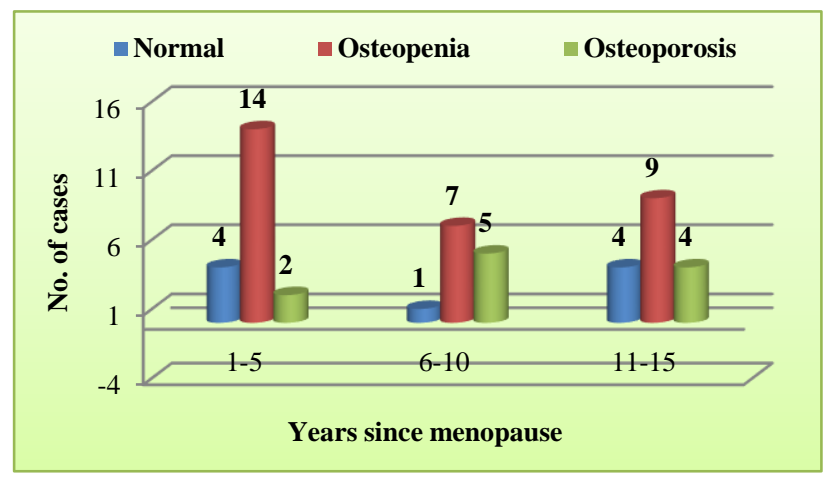

Figure 6: Correlation of duration of menopause with $t$ score forearm.

Maximum number of subjects who had osteoporosis and osteopenia were in the group which was not taking sufficient calcium in diet, that is less than $500 \mathrm{mg} /$ day. This was not found to be statistically significant $(\mathrm{p}>0.05)$.

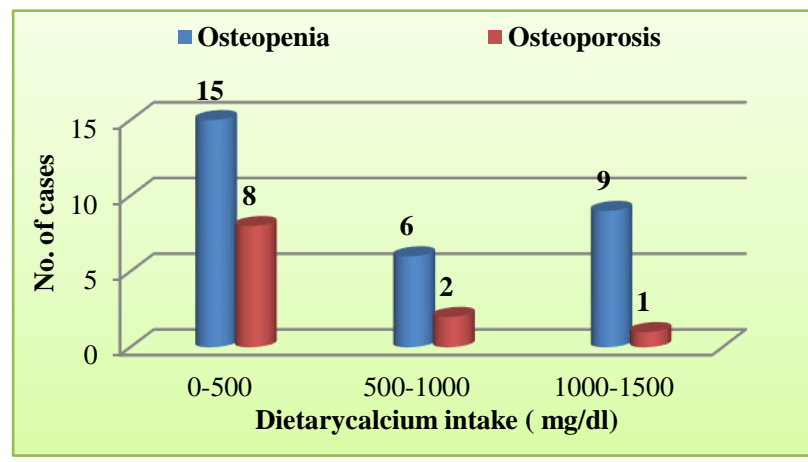

Figure 7: Correlation of dietary calcium with $\mathbf{T}$ score forearm.

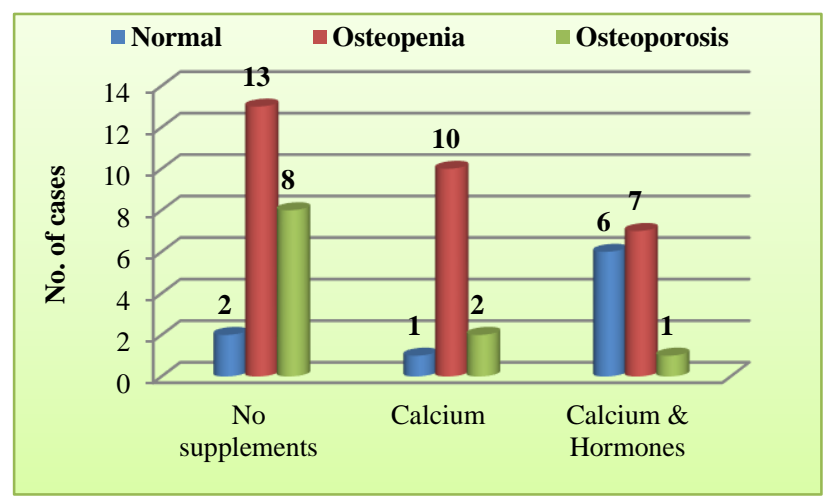

Figure 8: Correlation of calcium supplements with $\mathbf{T}$ score forearm.

8 subjects who developed osteoporosis and 13 subjects who developed osteopenia had not taken any calcium or 
hormonal supplements. Only one osteoporotic and 7 osteopenic subjects had taken calcium and hormone therapy in the past. Among normal subjects 6 had history of calcium and hormone intake in the past. There is positive correlation between supplements taken by subjects in the past and $\mathrm{T}$ score of forearm. This was found to be statistically significant.

In subjects consuming 2-3 cups of tea per day 7 were osteoporotic, 20 were osteopenic and 5 were normal. This was not found to be statistically significant $(\mathrm{p}>0.05)$.

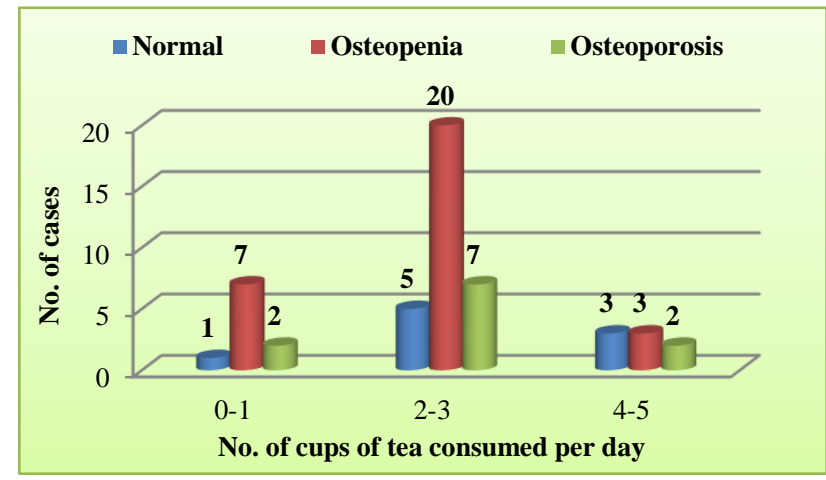

Figure 9: Correlation of tea consumption with $\mathbf{t}$ score forearm.

In subjects with sedentary lifestyle 14 had osteopenia and 5 had osteoporosis, whereas only 3 subjects who performed daily activity of more than 30 minutes were osteopenic.

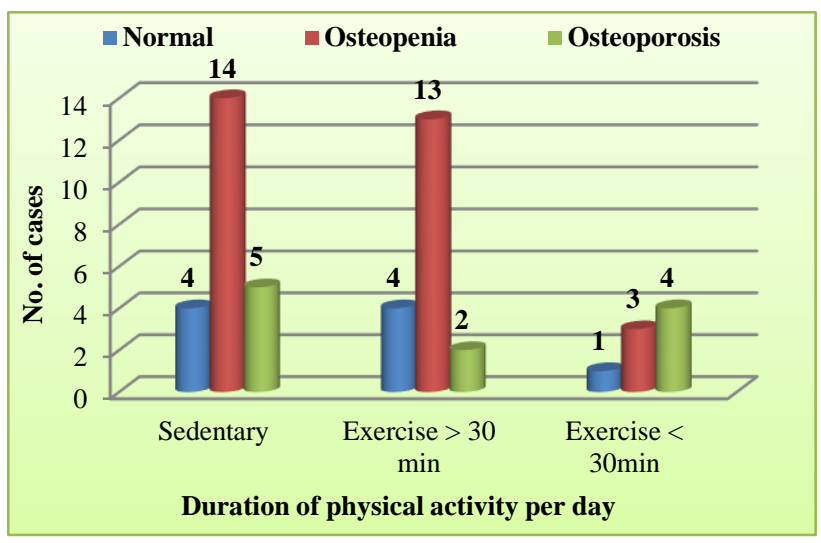

Figure 10: Correlation of physical activity with $\mathbf{T}$ score forearm.

Four subjects were osteoporotic with BMI $<25,5$ subjects were osteoporotic with BMI of 25.1-30 and 2 subjects were osteoporotic with BMI $>30 \mathrm{~kg} / \mathrm{m}^{2}$. This is not shown to be statistically significant.

The mean serum calcium level of the study subjects was $9.79+0.63 \mathrm{mg} / \mathrm{dl}$. On comparison of T score forearm with serum calcium levels, no statistical significance was observed.

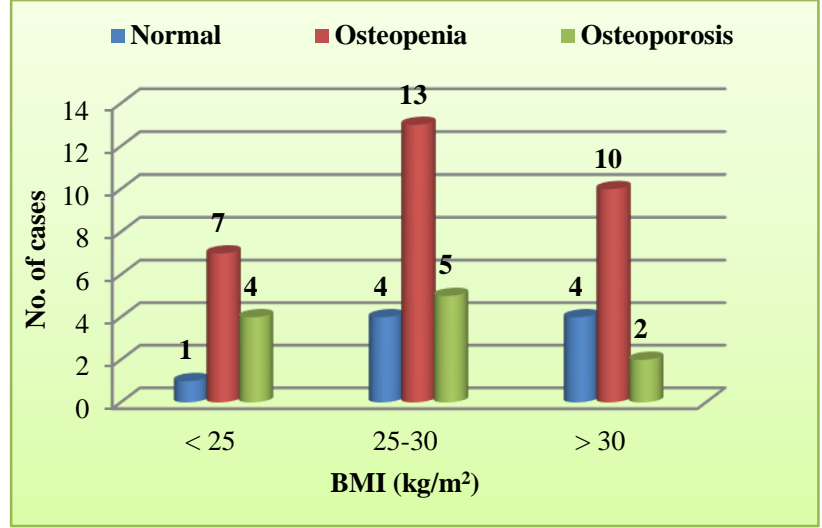

Figure 11: Correlation of body mass index with $\mathrm{T}$ score forearm.

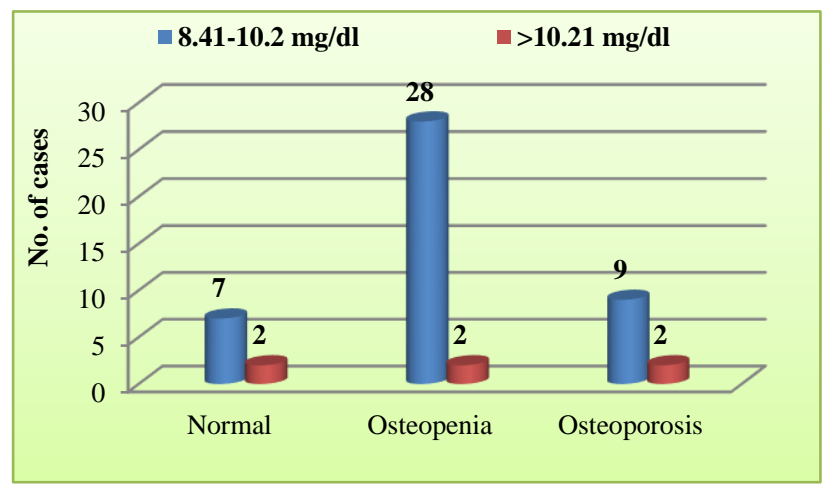

Figure 12: Correlation of serum calcium with $\mathrm{T}$ score forearm.

The mean phosphorus level of the study subjects was $4.06+0.54 \mathrm{mg} / \mathrm{dl}$. On comparison of T score forearm with serum phosphorus level, negative correlation was observed but it was not statistically significant.

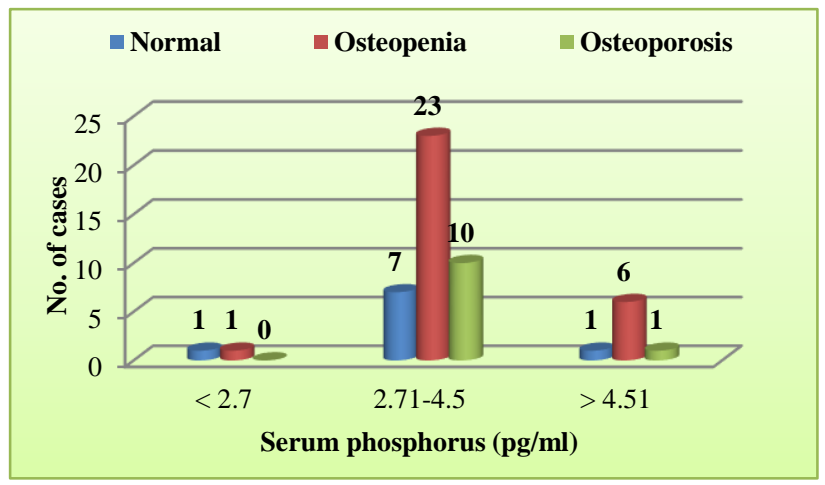

Figure 13: Correlation of serum phosphorus with $\mathrm{T}$ score forearm.

The mean serum alkaline phosphatase level of the study subjects was $92.26+49 \mathrm{mg} / \mathrm{dl}$. A negative correlation between $\mathrm{T}$ score forearm and alkaline phosphatase was observed, which means as levels of alkaline phosphatase increases, the $\mathrm{T}$ score forearm will decrease. This was statistically significant $(\mathrm{p}<0.05)$. 


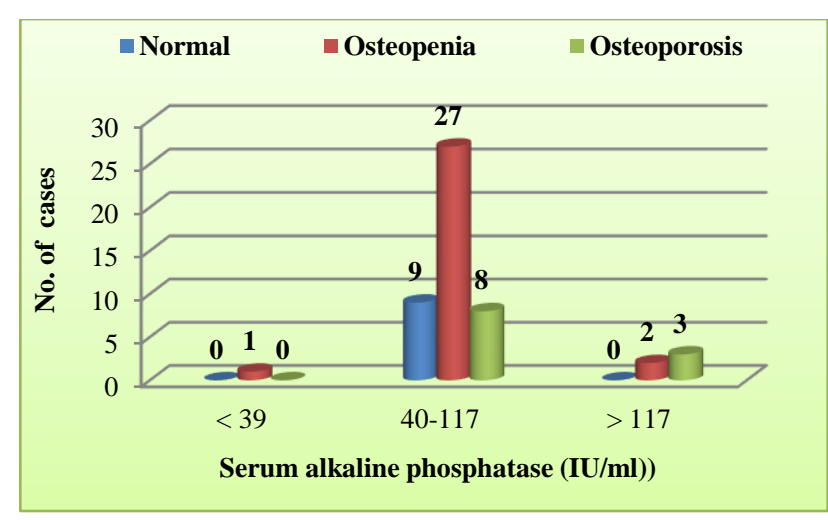

Figure 14: Correlation of serum alkaline phosphatase with $\mathbf{T}$ score forearm.

The mean level of PTH in the study subjects was $91.86 \mathrm{pg} / \mathrm{dl}$. On comparison of $\mathrm{T}$ score forearm with serum PTH negative correlation was seen which implies that with higher levels of serum PTH there will be low values of $\mathrm{T}$ score forearm. This was not statistically significant $(\mathrm{p}>0.05)$.

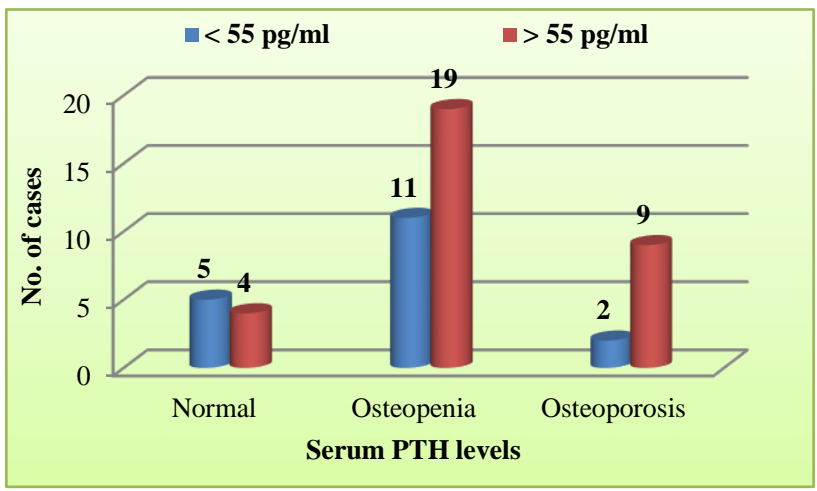

Figure 15: Correlation of serum parathyroid hormone with T score forearm.

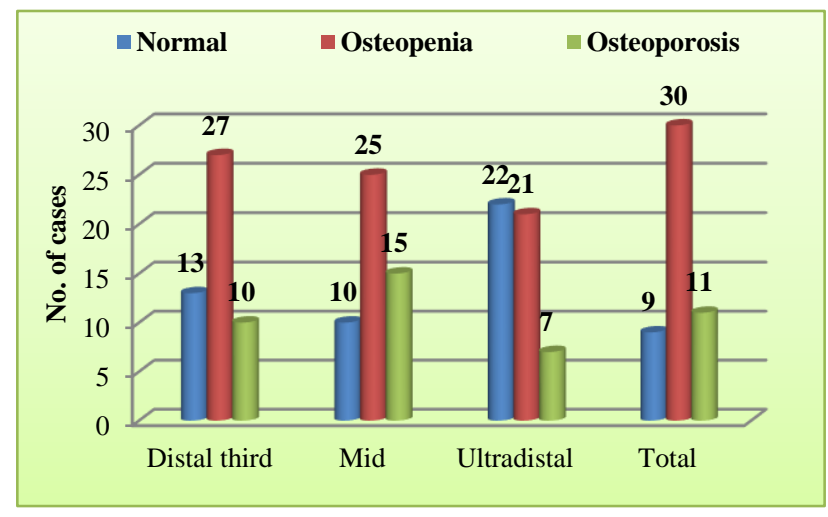

Figure 16: Correlation of $\mathrm{T}$ score at various sites in forearm.

There is statistically significant correlation between the T score of various sites of forearm such as ultradistal, distal third and mid-forearm $(\mathrm{p}<0.05)$. Fifteen subjects were osteoporotic by $\mathrm{T}$ score mid forearm whereas 7 were osteoporotic with $\mathrm{T}$ score ultradistal forearm and 11 subjects had osteoporosis with $\mathrm{T}$ score total forearm.

\section{DISCUSSION}

Life expectancy at birth has more than doubled in the last fifty years. The number of women in the postmenopausal age group is projected to increase from 36 million in 2000 to 63 million in $2020 . .^{9}$ As the life expectancy is increasing even in the developing countries, by the year 2035 the maximum number of osteoporosis cases in the world will be in India and China. ${ }^{10}$

The current study had shown that increasing age has negative correlation with T-score forearm. More number of osteoporotic subjects were in 56-60 years age group as compared to 46-50 years. This indicated that with increasing age of subjects, bone mineral density decreased and number of osteopenic and osteoporotic subjects increased. Similar effect was shown by Usha et al, Aggarwal et al, and Gandhi et al. ${ }^{11-13}$

Estrogen deficiency is undoubtedly one of the major causes of osteoporosis in postmenopausal women. ${ }^{14}$ In the study a higher number of osteopenic subjects were within 5 years of menopause and maximum number of subjects were osteoporotic between 6-10 years of menopause. This clearly pointed to significant inverse relationship of bone density with duration of menopausal years. This finding was similar to the previous studies reported in the literature. ${ }^{15,12}$

The major determinant of peak adult bone mass is the genetic influence. However, several studies have suggested that in addition to genetic and hormonal factors, calcium and vitamin D nutrition appears to have the greatest effect on bone mass, not only during growth period but also during adulthood and old ages. ${ }^{16}$

Dietary caffeine intake increases urinary and intestinal calcium secretion. Excessive consumption of caffeine containing drinks like coffee, tea may predispose to osteoporosis. Studies of coffee or caffeine as a potential risk factor for osteoporosis in women have given contradictory results. At least two studies suggest that this negative effect is limited to women who consume low levels of calcium.

In present study, none of the subjects consumed coffee and no association has been observed between the tea drinkers and $\mathrm{T}$ score forearm. This could be due to low caffeine content of tea and milk is usually added to the tea and the number of subjects consuming excessive tea was less.

The fact that no relationship was observed between current dietary calcium intake and bone density measurement, was consistent with that of some investigators but not with others who report positive association between calcium and bone. ${ }^{17,8}$ 
In the study, significant positive correlation between calcium supplementation and BMD is noticed. Less number of subjects were osteopenic and osteoporotic if they were taking calcium supplementation.

This was in accordance with Nicola et al who observed positive effect of calcium and vitamin D supplementation in both peri - and post- menopausal women. ${ }^{18}$ Prince et al had also reported beneficial effect of calcium supplementation on forearm bone. ${ }^{19}$ It is generally assumed that vitamin D deficiency or insufficiency should not occur in Indian living in India in view of ample exposure to sunlight. However increased skin pigmentation, crowded housing with limited sunlight exposure, social norms, smog, and the angle of ultraviolet light may limit the amount of vitamin D produced in skin. $^{3}$

In present study, it is evident that most of the subject had inadequate daily sun exposure with no vitamin D supplementation, hence we presume that subjects are vitamin $\mathrm{D}$ deficient. In the present study the mean serum calcium, phosphorus and alkaline phosphate levels were in the normal range where as the mean PTH level is 91.86 $\mathrm{pg} / \mathrm{ml}$ which was much higher compared to reference range of $9-55 \mathrm{pg} / \mathrm{ml}$. It has been suggested that increased concentrations of PTH might play an important role in the development of osteopenia in subjects.

The excess PTH increases bone remodelling, resulting ultimately in accelerated bone loss. Villareal etal demonstrated significant inverse correlation between PTH and vertebral bone density. ${ }^{20}$ Krall et al sshowed $\mathrm{BMD}$ at lumber spine, neck and intertrochanteric region of femur was inversely related to serum $\mathrm{PTH}^{21}$

Earlier studies found high correlation of BMD with BMI and an increase in BMD with an increase in BMI. ${ }^{22}$ In this study body weight and height were positively correlated with $\mathrm{T}$ score forearm and is statistically significant. This was similar to the study by Lurati and Laria which demonstrated positive association between bone density values and weight, height and BMI. ${ }^{23}$ The positive effect is seen at BMI of 26-28, but beyond a BMI of 30 , there is a negative impact on BMD. It has been hypothesized that this positive association between body size and BMD is due to adipose tissue. Most of the estrogen in postmenopausal women comes from the conversion of androgens to estrogen in adipose tissue, suggesting that those with more adipose tissue produce more estrogen and have less bone loss. Limitations of the study is a small sample size and single centre study. The reponses to the questionnaire were based on recall by menopausal patients.

\section{CONCLUSION}

In the Indian scenario, increasing life expectancy and issues like low calcium, vitamin D and micro nutrient intake, gender inequality, genetic predisposition have contributed to a high incidence of osteoporosis and morbidity among women. Therefore, in conclusion, it is important to optimise bone health by creating awareness about a healthy lifestyle not only during the peri- and post- menopausal age group but throughout a woman's life.

\section{Funding: No funding sources}

Conflict of interest: None declared

Ethical approval: The study was approved by the Institutional Ethics Committee

\section{REFERENCES}

1. Malhotra N, Mittal A. Osteoporosis in Indians. Indian J Med Res. 2008;127:265-8.

2. Anuradha VK, Rubina MM. Epidemiology and treatment of osteoposis in women: an indian perpective. Int J Women's Health. 2015;7:841-850.

3. Gupta A. Osteoporosis in India - The nutritional hypothesis. Natl Med J India. 1996;9(6):265-274.

4. Harinarayan CV. Prevalence of vitamin D insufficiency in postmenopausal south Indian women. Osteoporos Int. 2005;16(4):397-402.

5. Arya V, Bhambri R, Godbole MM, Mithal A. Vitamin D status and its relationship with bone mineral density in healthy Asian Indians. Osteoporos Int. 2004;15(1):56-61.

6. Haeney RP, Recker RR. Effects of nitrogen, phosphorus and caffeine on calcium balance in women. J Lab Clin Med. 1982;99:46-55.

7. Speroff L, Glass RH, Kase NG. Menopause and the Perimenopausal transition, In Clinical Gynecologic Endocrinology and Infertility, Lippincott Williams and Wilkins $6^{\text {th }}$ ed. 1999; 691-707.

8. Genant HK, Engelle K, Fuerest T, Glüer CC, Grampp S, Harris ST et al. Non invasive assessment of bone mineral and structure: state of art. J Bone Mineral Res. 1996;11(6):707-30.

9. Martin JC, Reid DM. Appendicular measurements in screening women for low axial bone mineral density. Br J Radiol. 1996;69:234-240.

10. Gnudi S, Malavolta N, Lisi L, Ripamonti C. Bone mineral density and bone loss measured at the radius to predict the risk of nonspinal osteoporotic fracture. J Bone Mineral Res. 2001;16(6):1130-5.

11. Usha G, Krishnaswamy B. Bone mineral density and fracture threshold in South Indian Elderly. J Assoc Physicians India. 2002;50:247-9.

12. Aggarwal N, Bathla S, Juneja S. Measurement of bone mineral density by dexa scan in post menopausal women. Obstet Gynecol Today. 2004;9(10):768-771.

13. Gandhi AB, Kumar A, Shukla R. Evaluation of BMD of women above 40 years of age. J Obstet Gynecol India. 2005;55(3):265-7.

14. ACOG Committee Opinion. Bone density screening for osteoporosis. Obstet Gynecol. 2002;99:523-5.

15. Savardekar LS, Rashmi SS, Umesh I, Danta B, Anand P, Bhavin J. Bone density in normal Indian 
women: Assessment by USG and DEXA. Obstet Gynecol Today. 2004;9:772-6.

16. Cavanaugh DJ, Cann CE. Brisk walking does not stop bone loss in postmenopausal women. Bone 1988;9:201-4.

17. Sandler RB, Slemenda CW, Laporte RE, Cauley JA, Schramm MM, Barresi ML et al. Post menopausal bone density and milk consumption in childhood and adolescence. Am J Clin Nutr. 1985;42:270-4.

18. Di Daniele N, Carbonelli MG, Candeloro N, Iacopino L, De Lorenzo A, Andreoli A. Effect of supplementation of calcium and vitamin $\mathrm{D}$ on bone mineral density and bone mineral content in peri-and post-menopause women: a double-blind, randomized, controlled trial. Pharmacologic Res. 2004 Dec 31;50(6):637-41.

19. Prince RL, Smith M, Dick IM, Price RI, Webb PG, Henderson NK et al. Prevention of postmenopausal osteoporosis. N Eng J Med. 1991;325:1189-95.

20. Villareal DT, Civitelli R, Chines A, Avioli LV. Subclinical vitamin D deficiency in postmenopausal women with low vertebral bone mass. J Clin Endocrinol Metab. 1991;72:628-34.

21. Krall EA, Hughes BD. Walking is related to bone density and rates of bone loss. Am J Med. 1994;96:20-26.

22. Sharma S, Khandelwal S. Effective risk assessment tools for osteoporosis in the Indian menopausal female. J Midlife Health. 2010;1(2):79-85.

23. Lurati, Laria. Relationship between Lumbar Bone Mineral Density (BMD) and Body Mass Index (BMI) in premenopausal population. a large chort study. Rheumatology. 2015;5:181.1000181.

Cite this article as: Sharma S, Agarwal B, Sharma $\mathrm{R}$, Singh S. Forearm bone mineral density in postmenopausal Indian women: correlation with calcium nutrition. Int J Reprod Contracept Obstet Gynecol 2017;6:4339-46. 